\title{
Analysis of Arginine, Glucose, Sucrose, and Polyethylene Glycols using a Wood Charcoal Matrix for MALDI-MS
}

\author{
Sunyoung Lee, Jinhee Kim, Hyo-Jik Yang, Seongjae Shin, Jangmi Hong, and Jeongkwon Kim* \\ Department of Chemistry, Chungnam National University, Daejeon, 305-764, Korea
}

Received November 1, 2010; Revised November 27, 2010; Accepted November 27, 2010

First published on the web December 15, 2010; DOI: 10.5478/MSL.2010.1.1.033

\begin{abstract}
Wood charcoal was investigated to determine its potential as an alternative matrix for matrix-assisted laser desorption/ ionization of various samples. Wood charcoal was an effective matrix for analyzing glucose, sucrose, arginine, and polyethylene glycols (PEGs), with detection levels of 100 pmol for glucose, $1 \mathrm{nmol}$ for sucrose, 100 pmol for arginine, 100 pmol for PEG 400 , 1 pmol for PEG 1540, and 10 pmol for PEG 3350. No analyte signal was observed for peptides or proteins.
\end{abstract}

Key words: Wood charcoal, Polyethylene glycol, Mass spectrometry, MALDI

\section{Introduction}

The analysis of samples using matrix-assisted laser desorption/ionization mass spectrometry (MALDI-MS) depends significantly on the MALDI matrix. The MALDI matrix carries on several important functions, such as energy transfer of the irradiated laser to analytes or suppression of intermolecular interactions between analytes by diluting the sample in high matrix-to-sample ratios, and assistance in the formation of protonated or ionic species of analytes. Currently, the most commonly used matrices are organic weak acids, such as 2,5-dihydroxy benzoic acid (DHB), $\alpha$-cyano-4-hydroxy cinnamic acid (CHCA), and sinapinic acid. However, these matrices are not well suited for measuring low molecular weight compounds, because they show abundant ion peaks of fragments, clusters, and the matrix itself in the low $\mathrm{m} / \mathrm{z}$ region. ${ }^{1,2}$ Additionally, MALDI is known to have poor reproducibility due to the heterogeneous solid crystal structure of the MALDI matrix. ${ }^{3}$ To overcome these limitations, many different materials have been used as alternative matrices in MALDI-MS, such as desorption ionization on silicon, ${ }^{4}$ binary matrices, ${ }^{5}$ ionic liquids, ${ }^{6}$ CHCA-modified Au nanoparticles, ${ }^{7}$ and carbon nanotubes. ${ }^{8}$

Graphite has also been used as a matrix in various ways. Sunner et al. used graphite particles $(2-150 \mathrm{~nm})$ with glycerol as a matrix to analyze bradykinin, cytochrome $c$, and a tryptic digest of cytochrome $c$. This technique was called surfaceassisted laser desorption/ionization mass spectrometry (SALDIMS), as opposed to MALDI-MS, which uses organic matrices? . The applicability of the combined graphite and liquid matrix was investigated to obtain high-quality mass spectra of peptides,

\footnotetext{
*Reprint requests to Dr. Jeongkwon Kim

E-mail: jkkim48105@cnu.ac.kr
}

proteins, oligosaccharides, and synthetic polymers ${ }^{10}$. Graphite was also coupled with a thin layer chromatography (TLC) plate for TLC-LDI. ${ }^{11}$

We investigate for the first time the applicability of wood charcoal as an alternative MALDI matrix for the analysis of various molecules. Charcoal has been defined by the International Union of Pure and Applied Chemistry (IUPAC) as "a traditional term for a char (a solid decomposition product of a natural or synthetic organic material) obtained from wood, peat, coal or some related natural organic material" ${ }^{12}$ Both graphite and wood charcoal consist of carbon, but they have different properties. Graphite has a layered crystal structure, whereas wood charcoal has a rough texture ${ }^{13}$ with many fine pores where bacteria or organic compounds can be absorbed. ${ }^{14}$

\section{Experimental}

\section{Materials}

Wood charcoal from oak was obtained at a local market. 1-arginine, l-cysteine, d-(+)-glucose, sucrose, $\mathrm{PEG}$ (average $\mathrm{M}_{\mathrm{n}}$ $\sim 400$ ), PEG (average $M_{n} \sim 1450$ ), PEG (average $M_{n} \sim 3350$ ), trifluoroacetic acid (TFA), sodium trifluoracetate (Na.TFA), acetonitrile $(\mathrm{ACN})$, adrenocorticotropic hormone (ACTH) 18-19, angiotensin I, and bradykinin were from SigmaAldrich (St. Louis, MO, USA). Acetone and methanol were from Merck (Whitehouse Station, NJ, USA).

\section{Sample preparation}

Charcoal was ground with a pestle and mortar, and the powder was washed with acetone, methanol, and distilled water, and then suspended in an aqueous solution of $50 \%$ ACN $/ 0.1 \%$ TFA by sonication for $15 \mathrm{~min}$. The concentration of the charcoal solution was $\sim 10 \mathrm{mg} / 100 \mu \mathrm{L}$. A stock solution of glucose, sucrose, arginine, or PEGs was prepared in $0.5 \%$ $\mathrm{TFA} /$ water at a concentration of $100 \mathrm{mM}$. A myoglobin 
stock solution $(10 \mathrm{mg} / \mathrm{mL})$ was prepared for protein analysis. The myoglobin stock solution was digested with trypsin at $37^{\circ} \mathrm{C}$ for $24 \mathrm{~h}$ with a protein-to-enzyme ratio of $50: 1$ to provide a peptide standard solution. Each of the stock solutions was serially diluted 10 -fold until no detectible signal was observed.

\section{MALDI-MS analysis}

The charcoal matrix solution $(1 \mu \mathrm{L})$ was deposited on a MALDI plate and dried at room temperature. Then, $1 \mu \mathrm{L}$ of analyte was placed on top of the matrix. In some experiments, $1 \mu \mathrm{L}$ of $10 \mathrm{mM} \mathrm{Na} \cdot \mathrm{TFA}$ or $10 \mathrm{mM} \mathrm{NaCl}$ was added to the top of the MALDI sample spots as a cationization agent for comparison. Mass spectra were obtained using a MALDI-TOF MS (Axima CFR, Shimadzu Biotech, 337-nm nitrogen laser) in positive ion reflection mode.

\section{Results and Discussion}

\section{Detection of glucose and sucrose}

Figure 1 shows the MALDI spectra of $10 \mathrm{nmol}$ glucose, where $1 \mu \mathrm{L}$ of $10 \mathrm{mM}$ glucose were added to the top of the
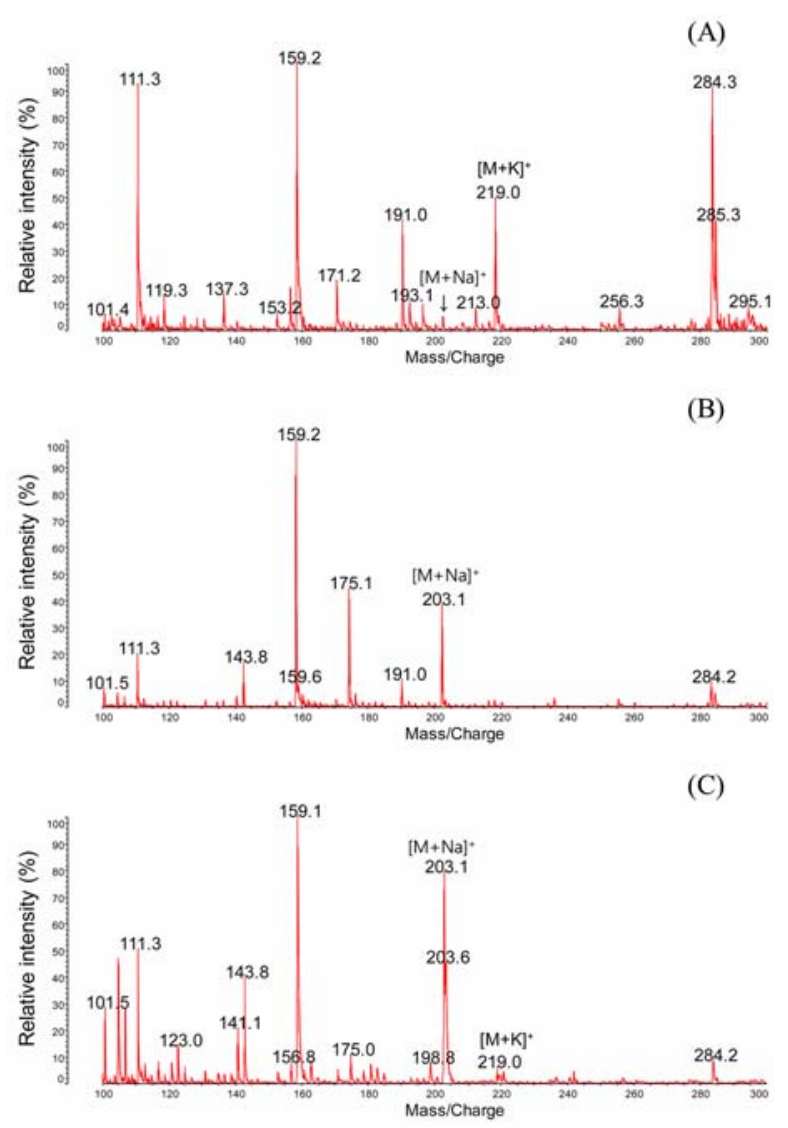

Figure 1. MALDI mass spectra of $10 \mathrm{nmol}$ glucose loaded to the top of wood charcoal matrix (A) without addition of sodium ions, (B) with addition of $\mathrm{Na} \cdot \mathrm{TFA}$, and (C) with addition of $\mathrm{NaCl}$. wood charcoal matrix solution $(1 \mu \mathrm{L})$ without addition of $\mathrm{Na}^{+}$(Figure 1A), with addition of Na.TFA (Figure 1B), and with addition of $\mathrm{NaCl}$ (Figure 1C). The peaks at $\mathrm{m} / \mathrm{z} 203.1$ and $m / z 219.0$ were assigned to $[\mathrm{M}+\mathrm{Na}]^{+}$and $[\mathrm{M}+\mathrm{K}]^{+}$, respectively. Protonated analyte ion was not observed. With no cationization agent, the peak intensity of the potassium adduct of glucose was more abundant than that of the sodium adduct, whereas the peak intensity of the sodium adduct was dominant compared with that of the potassium adduct when the sodium ion was added to the sample spot. The addition of $\mathrm{NaCl}$ resulted in greater ionization efficiency compared with the addition of Na.TFA. Glucose was detected at levels down to $10 \mathrm{nmol}, 1 \mathrm{nmol}$, and $100 \mathrm{pmol}$, with no cationization agent, with addition of $\mathrm{Na} \cdot \mathrm{TFA}$, and with addition of $\mathrm{NaCl}$, respectively.

Figure 2 shows the MALDI spectra of 100 nmol sucrose. In this experiment, $1 \mu \mathrm{L}$ of $100 \mathrm{mM}$ sucrose were added to the top of the wood charcoal matrix solution without addition of $\mathrm{Na}^{+}$(Figure 2A), with addition of Na.TFA (Figure 2B), and with additionof $\mathrm{NaCl}$ (Figure 2C). The peaks at $\mathrm{m} / z 364.6$ and $m / z 380.5$ were assigned to $[\mathrm{M}+\mathrm{Na}]^{+}$and $[\mathrm{M}+\mathrm{K}]^{+}$, respectively. When sucrose was analyzed without addition of
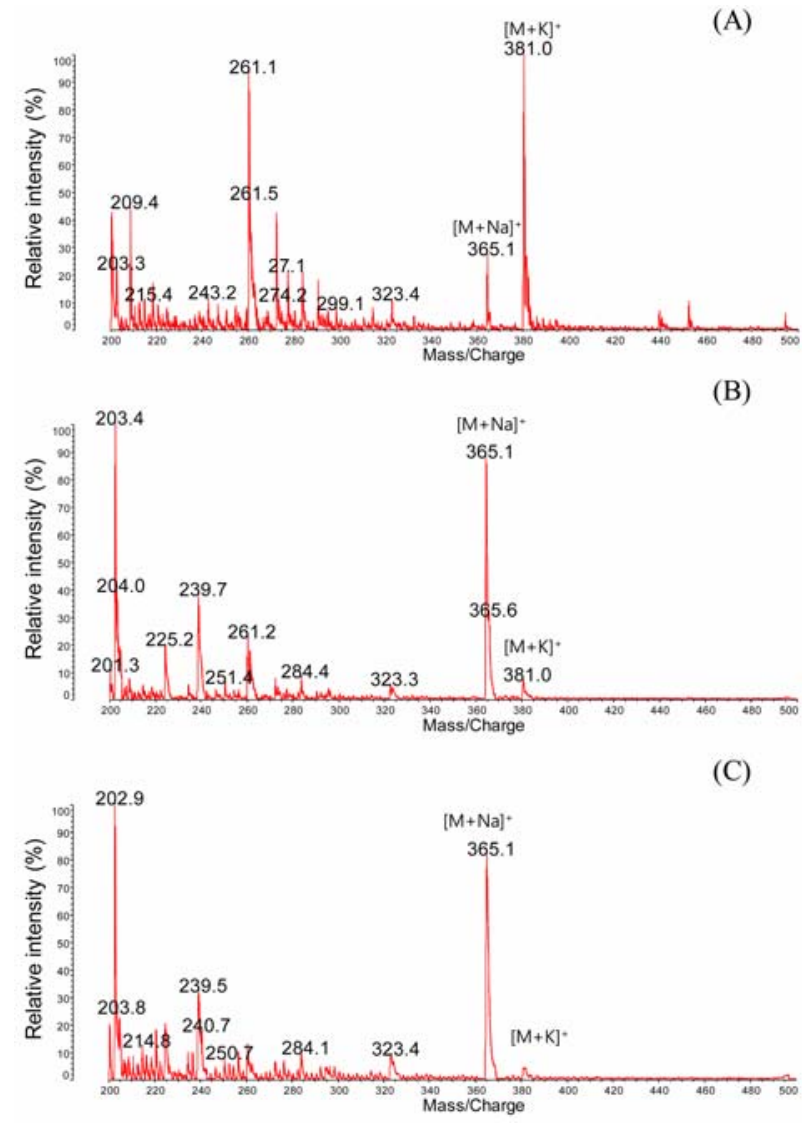

Figure 2. MALDI mass spectra of $100 \mathrm{nmol}$ sucrose loaded to the top of wood charcoal matrix (A) without addition of sodium ions, (B) with addition to $\mathrm{Na} \cdot \mathrm{TFA}$, and (C) with addition of $\mathrm{NaCl}$. 
$\mathrm{Na}^{+}$, the potassium adduct peak was dominant (Figure 2A). However, when $\mathrm{Na}^{+}$was added, the sodium adduct peak was dominant. The ionization efficiency of sucrose was better with addition of $\mathrm{NaCl}$ than with that of $\mathrm{Na}$. TFA. The lowest detection for sucrose was $10 \mathrm{nmol}$, with no addition of the cationization agent or with addition of $\mathrm{Na} \cdot \mathrm{TFA}$, and $1 \mathrm{nmol}$ with the addition of $\mathrm{NaCl}$.

Overall, for glucose and sucrose analysis, the addition of $\mathrm{NaCl}$ to the MALDI sample spots was more effective than the addition of Na.TFA. Compared with our previous investigation of glucose and sucrose with various supporting materials in LDI, ${ }^{15}$ the performance of wood charcoal as a supporting material was inferior, suggesting wood charcoal may not be well suited as a matrix for the analysis of glucose or sucrose.

\section{Detection of arginine, peptides, and proteins}

Figure 3 shows the MALDI spectra of arginine with different amounts loaded to the top of the wood charcoal matrix solution (Figure $3 \mathrm{~A}$ for $10 \mathrm{nmol}$, Figure $3 \mathrm{~B}$ for $1 \mathrm{nmol}$. and Figure $3 \mathrm{C}$ for $100 \mathrm{pmol})$. The protonated arginine peak was
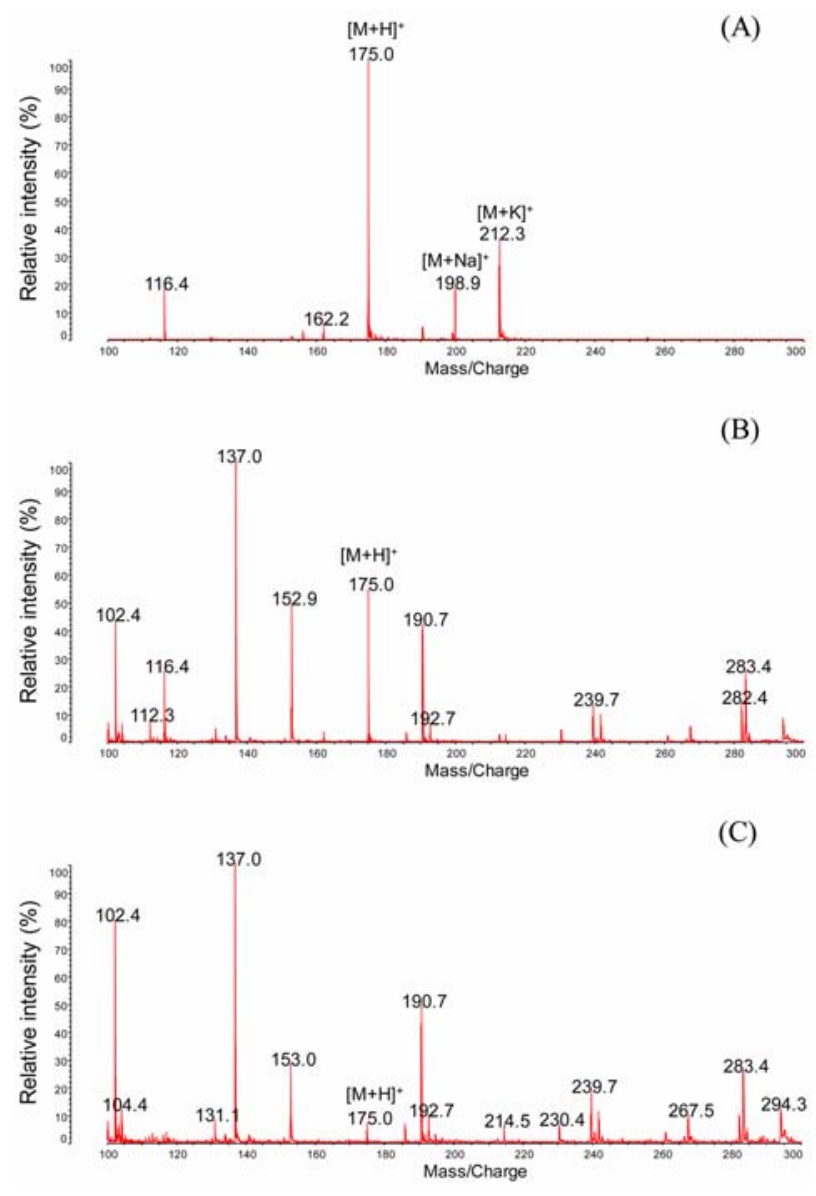

Figure 3. MALDI mass spectra of arginine loaded to the top of wood charcoal matrix in loading amounts of (A) $10 \mathrm{nmol}$, (B) $1 \mathrm{nmol}$, or (C) 100 pmol. dominant at $10 \mathrm{nmol}$, followed by the potassium adduct peak and then by the sodium adduct peak. When the loading amounts decreased, the two adduct peaks disappeared. The lowest detection for arginine was 100 pmol.

A standard protein (myoglobin) and its tryptic digest were analyzed using wood charcoal as a matrix. No peak of protein or peptide was observed in any concentration range. Seemingly, wood charcoal was not an effective material for LDI of proteins and peptides, because no energy transfer from the wood charcoal to the samples occurred. It is also possible that the samples are trapped inside the porous holes of the wood charcoal because wood charcoal has numerous fine holes that can trap organic compounds. ${ }^{14}$

\section{Detection of PEGs}

Figure 4 shows the MALDI MS spectra of PEG 400, PEG 1450, and PEG 3350. The ionization efficiency of PEG samples was significantly improved with the addition of $\mathrm{Na}^{+}$. The addition of Na.TFA was more effective than that of $\mathrm{NaCl}$. It was difficult to analyze PEG samples with molar masses
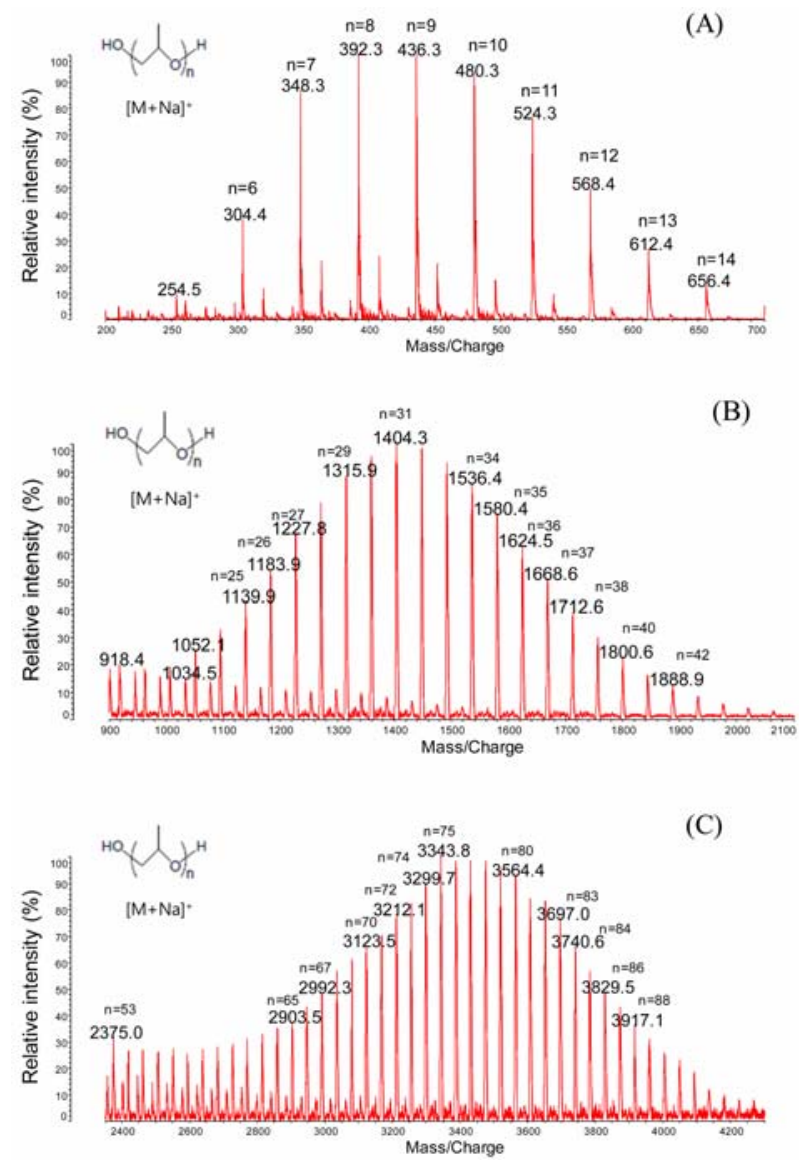

Figure 4. MALDI mass spectra of (A) 10 nmol PEG 400, (B) 1 nmol PEG 1450, and (C) 1 nmol PEG 3350. Each MALDI spot was prepared by loading each PEG on the top of wood charcoal matrix on the MALDI plate, followed by the addition of Na.TFA. 
greater than $8000 \mathrm{Da}$. PEG 400, PEG 1450, and PEG 3350 were successfully detected with the addition of Na·TFA down to $100 \mathrm{pmol}, 1 \mathrm{pmol}$, and $10 \mathrm{pmol}$, respectively. The PEG 8000 sample was not detected.

\section{Conclusions}

In this study, wood charcoal was successfully applied as an alternative matrix in MALDI to analyze glucose, sucrose, arginine, and PEGs. Glucose and sucrose showed a low detection limits with the addition of $\mathrm{NaCl}$. On the other hand, polyethylene glycols had a low detection limits with the addition of Na.TFA. The detection limits were $100 \mathrm{pmol}$ for glucose, $1 \mathrm{nmol}$ for sucrose, 100 pmol for arginine, $1 \mathrm{nmol}$ for PEG 400, 1 pmol for PEG 1450, and 10 pmol for PEG 3350. No signal was observed for peptides or proteins.

\section{References}

1. Kinumi, T.; Saisu, T.; Takayama, M.; Niwa, H. J. Mass Spectrom. 2000, 35, 417.

2. Wu, H. P.; Su, C. L.; Chang, H. C.; Tseng, W. L. Anal. Chem. 2007, 79, 6215.
3. Laugesen, S.; Roepstorff, P. J. Am. Soc. Mass Spectrom. 2003, 14, 992.

4. Wei, J.; Buriak, J. M.; Siuzdak, G. Nature 1999, 399, 243.

5. Soltwisch, J.; Berkenkamp, S.; Dreisewerd, K. Rapid Commun. Mass Spectrom. 2008, 22, 59.

6. Fukuyama, Y.; Nakaya, S.; Yamazaki, Y.; Tanaka, K. Anal. Chem. 2008, 80, 2171.

7. Duan, J. C.; Linman, M. J.; Chen, C. Y.; Cheng, Q. J. J. Am. Soc. Mass Spectrom. 2009, 20, 1530.

8. Xu, S. Y.; Li, Y. F.; Zou, H. F.; Qiu, J. S.; Guo, Z.; Guo, B. C. Anal. Chem. 2003, 75, 6191.

9. Sunner, J.; Dratz, E.; Chen, Y. C. Anal. Chem. 1995, 67, 4335.

10. Dale, M. J.; Knochenmuss, R.; Zenobi, R. Anal. Chem. 1996, 68, 3321.

11. Peng, S.; Edler, M.; Ahlmann, N.; Hoffmann, T.; Franzke, J. Rapid Commun. Mass Spectrom. 2005, 19, 2789.

12. Fitzer, E.; Kochling, K. H.; Boehm, H. P.; Marsh, H. Pure Appl. Chem. 1995, 67, 473.

13. Harris, P. Interdiscip. Sci. Rev. 1999, 24, 301.

14. Agbanobi, R. O. J. Environ. Qual. 1999, 28, 1038.

15. Yang, H. J.; Lee, A.; Lee, M. K.; Kim, W.; Kim, J. Bull. Korean Chem. Soc. 2010, 31, 35. 